\title{
HIDUP BERSIH DAN SEHAT DENGAN PROGRAM JAMBANISASI
}

\author{
Olifiani Nurul Malida ${ }^{1}$, Ilfa Nihlatika ${ }^{1}$, Novi Indah Lestari ${ }^{1}$, Ahmad Fauzan Hidayatullah ${ }^{2}$ \\ ${ }^{1}$ Departemen Psikologi, Fakultas Psikologi dan Kesehatan, Universitas Islam Negeri \\ Walisongo Semarang. Jl. Prof. Dr. Hamka No.3 - 5, Tambakaji, Kec. Ngaliyan, Kota \\ Semarang, Jawa Tengah 50185, \\ ${ }^{2}$ Departemen Pendidikan Biologi, Fakultas Sains dan Teknologi, Universitas Islam Negeri \\ Walisongo Semarang. Jl. Prof.Dr. Hamka Km 2 Kampus 2 Universitas Islam Negeri \\ Walisongo Semarang \\ Email : olifiani_1807016010@student.walisongo.ac.id: \\ ilfanihlatika_1807016020@students.walisongo.ac.id; \\ noviindahlestari_1807016035@students.walisongo.ac.id
}

\section{CLEAN AND HEALTHY LIVES WITH THE JAMBANIZATION PROGRAM}

\begin{abstract}
Clean and healthy environmental conditions greatly affect the health of the community such as the provision of clean water, latrines in every family, and environmental conditions around the house. This study aims to find out how to live clean and healthy with a latrine program. Through a latrine program it will increase awareness of the negative effects of open defecation. This condition has greatly reduced sanitation in the surrounding environment. This research method uses the literature review method. To maintain accuracy of the assessment and prevent misinformation in data analysis, checking is done between libraries and rereading the libraries. The results of this study are there are still some people who have an attitude that does not agree even do not agree to use the toilet, do not have a toilet, so it does not rule out the transmission of various diseases will occur.
\end{abstract}

Keywords: Clean and Healthy Behavior, Sanitation, and Latinization

\begin{abstract}
Abstrak
Kondisi lingkungan yang bersih dan sehat sangat berpengaruh terhadap kesehatan di masyarakat seperti penyediaan air bersih, jamban disetiap keluarga, serta kondisi lingkungan di sekitar rumah. Penelitian ini bertujuan untuk mengetahui bagaimana hidup bersih dan sehat dengan program jambanisasi. Melalui program jambanisasi akan meningkatkan kesadaran akan dampak negative dari buang air besar sembarangan. Kondisi tersebut sangat menurunkan sanitasi di lingkungan sekitar. Metode penelitian ini menggunakan metode telaah pustaka. Untuk menjaga ketepatan pengkajian dan mencegah kesalahan informasi dalam analisis data maka dilakukan pengecekan antar pustaka dan membaca ulang pustaka. Hasil penelitian ini adalah masih ada sebagian masyarakat yang memiliki sikap yang kurang setuju bahkan tidak setuju untuk menggunakan jamban, tidak memiliki jamban, sehingga tidak menutup kemungkinan penularan berbagai macam penyakit akan terjadi.
\end{abstract}

Kata Kunci: Perilaku Hidup Bersih dan Sehat, Sanitasi, dan Jambanisasi 


\section{PENDAHULUAN}

Perkembangan zaman pada saat ini memberikan peran penting bagi kehidupan manusia dimana teknologi yang semakin canggih memudahkan manusia untuk mengakses bebagai macam informasi terutama mengenai masalah kesehatan dan kerbersihan. Perilaku hidup bersih dan sehat harus diterapkan agar masyarakat menjadi sehat, anak-anak akan tumbuh cerdas dalam lingkungan yang sehat, masyarakat akan lebih mampu mewujudkan lingkungan yang bersih sehat serta mampu mencegah dan menanggulangi penyakit dan masalah kesehatan dilingkungan sekitar mayarakat. Pelaksanaan kegiatan kesehatan dan kebersihan sudah banyak diterapkan di lingkungan masyarakat, dimulai dari memberikan contoh kepada anak-anak kecil untuk membuang sampah pada tempatnya, mencuci tangan setalah melakukan aktivitas baik di luar rumah maupun di dalam rumah. Kegiatan hidup sehat dan bersih tidak hanya untuk anak-anak saja tetapi juga untuk para remaja, bapak-bapak maupun ibu-ibu dari berbagai kalangan usia.

Menurut Proverawati dan Rahmawati (2012:1), perilaku hidup sehat merupakan cerminan pola hidup keluarga yang senantiasa memperhatikan dan menjaga kesehatan anggota seluruh keluarga. Perilaku hidup bersih dan sehat merupakan perilaku yang dilakukan atas dasar kesadaran orangorang terhadap kepedulian lingkungan sehingga mampu menjaga lingkungannya tetap bersih dan sehat. Perilaku hidup bersih dan sehat merupakan bentuk perwujudan dari upaya untuk memberikan menciptakan suatu kondisi yang kondusif, nyaman,aman perorangan, keluarga, dan masyarakat.

Menurut Organisasi Kesehatan Dunia (WHO) dalam Notoatmodjo (2005:2), bahwa kesehatan adalah "keadaan sempurna baik fisik, mental, maupun social, dan tidak hanya bebas dari penyakit dan cacat. Dalam UU Kesehatan RI No.36 Tahun 2009,'Kesehatan adalah keadaan sehat baik fisik, mental, spiritual maupun social yang memungkinkan setiap orang untuk hidup produktif secara social dan ekonomis". Kebutuhan dasar manusia adalah tersedianya air bersih.

PBB dirikan MDG pada tahun 2000 untuk menetapkan target global mengenai delapan sasaran kemiskinan, kelaparan, kematian ibu dan anak, penyakit menular, kemudahan pendidikan, ketidaksetaraan gender, kerusakan lingkungan, dan kemitraan global. Pada 2017, 785 juta orang masih kekurangan air minum. 206 juta orang menghabiskan lebih dari 30 menit per perjalanan pulang pergi untuk mengambil air dari sumber yang lebih baik dan sisanya 
bergantung sumber air permukaan (WHO dan UNICEF, 2019)

Zaman sekarang yang sudah canggih masih ada orang yang memiliki perilaku yang buruk yaitu perilaku buang air besar sembarangan. Tujuan pembangun berkelanjutan Sustainable Development Goals (SDGS) memiliki satu point penting pada sector lingkungan hidup yaitu memastikan masyarakat mencapai akses universal air bersih dan sanitasi dasar yaitu jamban sehat.

Berdasarkan data dari World Health Organization (WHO) pada tahun 2013 diperkirakan sebesar 1,1 milyar orang atau 17\% penduduk dunia masih Buang Air Besar (BAB) di area terbuka, dari data tersebut sebesar $81 \%$ penduduk yang Buang Air Besar Sembarangan (BABS) terdapat di 10 negara dan Indonesia sebagai negara kedua terbanyak ditemukan masyarakat buang air besar di area terbuka, yaitu India (58\%), Indonesia (12,9\%), China (4,5\%), Ethiopia $(4,4 \%)$, Pakistan $(4,3 \%)$, Nigeria (3\%), Sudan $(1,5 \%)$, Nepal $(1,3 \%)$, Brazil $(1,2 \%)$ dan Nigeria $(1,1 \%)$ (WHO, 2014).Terdapat 24 juta keluarga di Indonesia yang saat ini belum mempunyai jamban (BPS,2015). Kondisi seperti ini disebabkan karena program sanitasi masih berorientasi pada target fisik serta belum berorientasi pada perubahan perilaku di masyarakat (Rahamwati\& Soedirham,2013).

Penggunaan jamban di Indonesia masih rendah, hal tersebut dilaporkan oleh Badan Pusat Statistik (BPS) tahun 2014 tercatat penduduk yang menggunakan jamban rumah tangga sendirisebanyak $65,8 \%$ dan yang tidak memiliki jamban sendiri sebanyak $34,2 \%$. Kurangnya kepemilikan jamban oleh masyarakat mengakibatkan lingkungan yang kurang bersih dan sehat.

\section{BAHAN DAN METODE}

Pada penelitian ini kami menggunakan jenis/pendekatan penelitian yang berupa Telaah Pustaka (Literature Review). Telaah pustaka adalah kajian yang mendalam atas pembahasan suatu topik yang sudah ditulis oleh para peneliti atau ilmuwan yang telah diakui kepakarannya. Telaah pustaka bertujuan menyampaikan kepada pembaca pengetahuan dan ide apa saja yang sudah dibahas dalam suatu topik penelitian.

\section{HASIL}

\section{A. Perilaku Hidup Sehat dan Bersih}

Perilaku dari segi biologis adalah suatu kegiatan atau aktivitas yang dilakukan oleh makluk hidup, perilaku manusia pada hakekatnya adalah aktivitas yang dilakukan oleh manusia sendiri seperti berjalan, 
menangis, berbicara, tertawa, bekerja, adalah sekumpulan perilaku yang membacadan lain-lain. Perilaku yang tidak dipraktikkan atas dasar kesadaran sebagai terlihat seperti berfikir, emosi, persepsi, dan hasil pembelajaran, yang menjadikan lain-lain. Perilaku (manusia) adalah semua seseorang, keluarga, masyarakat mampu kegitan atau aktivitas manusia, baik yang menolong dirinya sendiri di bidang kesehatan dapat diamati langsung, maupun yang tidak dan berperan aktif dalam mewujudkan dapat diamati langsung oleh pihak luar kesehatan masyarakat (Kementrian (Notoatmodjo,2000).

Perilaku yang ada pada individu tidak ada atau tidak muncul dengan sendirinya, melainkan timbul akibat dari adanya stimulus yang mengenai indivitu tersebut. Perilaku merupakan jawaban atau respon terhadap stimulus yang ada, sedangkan respon merupakan fungsi yang tergantung pada stimulus dan individu (Wood worth \& Schlosberg, 1971 dalam Walgito,2004).

Perilaku Hidup Bersih dan Sehat (PHBS) merupakan bentuk perwujudan paradigma sehat dalam budaya perorangan. Keluarga dan masyarakat yang berorientasi sehat, bertujuan untuk memelihara, melindungi dan meningkatkan kesehatannya baik dari segi fisik, mental, spritual maupun social (Depkes RI,2002).

Perilaku Hidup Sehat dan Bersih (PHBS) adalah seluruh perilaku kesehatan yang dilakukan atas kesadaran, sehingga anggota keluarga dan anggota keluarga dapat menolong dirinya sendiri di bidang kesehatan. Perilaku Hidup Bersih dan Sehat Kesehatan RI, 2011). Kebijakan Nasional promosi kesehatan telah menetapkan tiga strategi dasar promosi kesehatan dan PHBS yaitu :

1. Gerakan Pemberdayaan

Pemberdayaan merupkan proses pemberian informasi secara terus-terus mengikuti perkembangan sasaran agar sasaran tersebut dapat merubah dirinya dari yang tidak tahu menjadi tahu (aspek knowledge), dari tahu menjadi mau (aspek attitude), dapat melaksanakan perilaku yang telah diperkenalkan (aspek practice).

2. Bina Suasana

Bina Suasana merupakan upaya untuk menciptakan lingkungan social masyarakat yang mendorong individu untuk melakukan perilaku yang telah diperkenalkan. Terdapat tiga pendekatan dalam bina suasana yakni pendekatan individu, pendekatan kelompok, dan pendekatan masyarakat umum. 
3. Advokasi

Advokasi merupakan proses yang terencana untuk mendapatkan dukungan dari pihak - pihak yang terkait.

Tujuan Perilaku Hidup Bersih dan Sehat adalah untuk meningkatkan pengetahuan, kesadaran, kemauan, dan kemampuan masyarakat untuk hidup bersih dan sehat, serta meningkatkan peran aktif masyarakat termasuk dunia usaha, dalam upaya mewujudkan derajat kesehatan yang optimal (Depkes RI, 1997).

Menurut Lawrence Green (1980), dalam Notoatmodjo (2007), dalam Jariston (2009), terdapat tiga faktor penyebab mengapa seseorang melakukan Perilaku Hidup Bersih dan Sehat (PHBS) yaitu :

1. Faktor Pemudah

Faktor yang mecakup tentang pengetahuan dan sikap anak-anak terhadap perilaku hidup bersih dan sehat. Faktor ini menjadi pemicu terhadap perilaku yang menjadi dasar bagi tindakannya akibat kebiasaan, kepercayaan, tingkat pendidikan dan tingkat social ekonomi.

2. Faktor Pemungkin

Faktor pemicu terhadap perilaku yang memungkinkan suatu motivasi terlaksana. Faktor yang mencakup ketersediaan sarana dan prasarana kesehatan bagi anakanak, misalnya air bersih, tempat pembuangan sampah jamban, ketersediaan makanan bergizi dan lain-lain. Fasilitas ini akan mampu mendukung perilaku hidup bersih dan sehat.

\section{Faktor Penguat}

Faktor yang menentukan tindakan kesehatan memperoleh dukungan atau tidak. Faktor ini terwujud dalam bentuk sikap dan perilaku pengasuh anak-anak atau orang tua yang merupakan tokoh yang dipanuti oleh anak.

Menurut Depkes RI (2002), dalam Jariston (2009), manajemen Prilaku Hidup Bersih dan Sehat adalah penerapan keempat proses manajemen pada umumnya kedalam model pengkajian dan penindaklanjutan berikut ini :

1. Kualitas hidup adalah sasaran utama yang ingin dicapai dibidang pembangunan sehingga kualitas hidup ini sejalan dengan tingkat kesejahteraan.

2. Derajat kesehatan adalah sesuatu yang ingin dicapai dalam bidang kesehatan, dimana dengan adanya derajat kesehatan akan tergambarkan masalah kesehatan yang sedang dihadapi. Faktor yang paling berpengaruh terhadap derajat kesehatan seseorang adalah faktor perilaku dan faktor lingkungan. 
3. Faktor lingkungan adalah faktor fisik, dan kurangnya akses ke produk dan layanan biologis dan social budaya yang langsung atau tidak mempengaruhi derajat kesehatan.

4. Faktor perilaku dan gaya hidup adalah suatu faktor yang timbul karena adanya aksi dan reaksi seseorang terhadap lingkungannya.

\section{B. Sanitasi}

Sanitasi merupakan salah satu aspek pembangunan yang memiliki fungsi penting untuk menunjang tingkat kesejahteraan bagi masyarakat. Karena sanitasi ini berkaitan dengan kesehatan, pola hidup, kondisi lingkungan pemukiman serta kenyamanan dalam lingkungan. Sanitasi yang baik dapat mengurangi penularan bakteri yang bisa menyababkan diare dengan cara mencegah kontaminasi tinja manusia dengan lingkungannya. Dengan meningkatkan sarana sanitasi bisa mengurangi penyakit diare dan dengan menggunakan jamban yang efektif juga bisa mengurangi penyakit diare.

Tujuan dari SDG mengenai sanitasi adalah untuk memberitahu bagaimana mengakhiri buang air besar sembarangan. Sementara itu, perbaikan sanitasi pedesaan yang berkelanjutan banyak mengalami kendala, seperti keuangan sumber daya untuk sanitasi tidak memadai, kurangnya komitmen politik, sanitasi. Selain itu, banyak daerah yang gagal melakukan upaya pembangunan ini, dikarenakan masyarakatnya tidak menghargai, menggunakan, ataupun memelihara fasilitas yang telah diberikan. Adapun Sanitasi Total Berbasis Masyarakat merupakan salah satu cara yang paling banyak digunakan, yaitu dengan memanfaatkan penggerak emosional seperti rasa jijik, taku, malu, hingga memiliki rasa kebanggaan dan martabat yang mengarahkan masyarakat untuk menghentikan buang air besar sembarangan. Meskipun cara ini sudah diperkenalkan diberbagai Negara, tetapi penerapannya belum ada.

Banyak dari kaum perempuan dan anak-anak bersaing dengan adanya fasilitas sanitasi yang tidak ditingkatkan. Dan akhirnya mereka balas dendam dalam kemampuannya menjaga kebersihan mereka sendiri dan keluarga mereka. Tingkat akses terhadap air bersih yang berbeda dapat berdampak pada individu dan rumah tangga melalui jslur penularan penyakit. Untuk mendapatkan air bersih mereka harus berjalan jauh menuju sumber air. Secara tidak langsung pengambilan air tersebut bisa menyebabkan kesehatan semakin memburuk. Karena kaum perempuan dikeluarga miskin paling sering ditugaskan untuk mengambil air. Waktu dan 
energy yang digunakan untuk mengambil air akan mengurangi peluang bagi perempuan untuk berbelanja dan pergi ke klinik kesehatan. Dengan adanya pasokan air dan sanitasi didalam rumah akan memungkinkan kaum wanita untuk menerima dukungan sosial yang kemudian dapat memfasilitasinya dengan perawatan kesehatan atau untuk bepergian. Maka dari itu, adanya pasokan air yang tidak ditingkatkan serta perbaikan yang rendah terhadap penggunaan sanitasi terbukti dapat berpengaruh pada individu maupun rumah tangga dan lingkungan yang ada disekitarnya.

Nutrisi, pendidikan dan kesetaraan dan akses air minum yang aman serta system sanitasi yang efektif dan praktik kebersihan yang baik memiliki konstribusi pada peningkatan kesehatan masyarakat dalam menuju pencapaian Tujuan Pembangunan Berkelanjutan (SDGs). Namun, ada laporan terbaru apakah fasilitas sanitasi merupakan tindakan efektif untuk meningkatkan kesehatan pada masyarakat atau tidak. Telah dilakukan percobaan di India yang menunjukan bahwa peningkatan jamban tidak mengurangi adanya paparan kontaminasi tinjau atau mencegah diare, infeksi cacing yang ditularkan melalui tanah, atau kekurangan gizi pada anak ( Clasen et al..2014).
Di daerah pedesaan, kepadatan populasi lebih rendah dan begitu pula dengan lingkungan dapat lebih mudah menyerap dan memecah yang lebih rendah volume dan konsentrasi kotoran Beberapa penelitian telah mengevaluasi secara ketat manfaat kesehatan masyarakat dari pembangunan jamban di area pedesaan. Di daerah pedesaan, mendukung pembangunan dan penggunaan jamban yang berkualitas.

Pedesaan mengembangkan strategi yang lebih efektif untuk lebih sering menggunakan jamban, mengembangkan strategi yang efektif untuk penahanan kotoran, dan evaluasi dampak kesehatan yang lebih baik.

Banyak orang memiliki toilet, tetapi tinja yang terkumpul di toilet ini dibuang kembali ke lingkungan yang tidak dirawat karena bocor atau rusak toilet, sengaja oleh operator truk vakum atau melalui saluran terbuka atau pipa drainase yang mengalirke badan air permukaan setempat.

Rumah sehat adalah harus memenuhi sarana kesehatan lingkungan yaitu penyediaan air bersih, pembuangan kotoran, pembuangan air limbah, dan pembuangan sampah. Pembuangan kotoran dalam hal ini pembuangan tinja atau ekskreta manusia merupakan bagian yang penting dari sanitasi lingkungan. Penggunaan jamban merupakan 
salah satu masalah kesehatan yang penting. ada genangan air, bersihkan jamban secara Pembuangan tinja manusia yang terinfeksi teratur sehingga ruang jamban selalu dalam yang dilaksanakan secara tidak layak tanpa memenuhi syarat sanitasi dapat keadaan bersih, didalam jamban tidak ada menyebabkan terjadinya pencemaran tanah dan sumber penyediaan air bersih.

Di samping itu juga akan memberi kesempatan bagi lalat dari spesies tertentu untuk bertelur, bersarang, makan bagian tersebut serta membawa infeksi, menarik hewan ternak, tikus serta serangga lain yang dapat menyebabkan tinja dan kadang-kadang menimbulkan bau yang tidak enak. Tujuan digunakan jamban yakni untuk penanganan pembuangan tinja yang memenuhi persyaratan sanitasi adalah untuk merangsang serta mengisolir tinja sedemikian rupa sehingga dapat mencegah masalah dalam bidang kesehatan dan sebagai media bibit penyakit, seperti diare, typhus, muntaber, disentri, cacingan dan gatal-gatal. Selain itu dapat menimbulkan pencemaran lingkungan pada sumber air dan bau busuk serta estetika.

Jamban keluarga adalah suatu bangunan yang dipergunakan untuk membuang tinja atau kotoran manusia atau najis bagi suatu keluarga yang lazim disebut kakus atau WC. Pemeliharaan jamban keluarga sehat yang baik adalah lantai jamban hendaknya selalu bersih dan tidak kotoran terlihat, tidak ada serangga (kecoak, lalat) dan tikus berkeliaran, tersedia alat pembersih dan bila ada kerusakan segera diperbaiki.

Syarat jamban yang sehat sesuai kaidah-kaidah kesehatan adalah tidak mencemari sumber air minum, tidak berbau tinja dan tidak bebas dijamah oleh serangga maupun tikus, air seni, air bersih dan air penggelontor tidak mencemari tanah sekitar olehnya itu lantai sedikitnya berukuran $1 \times 1$ meter dan dibuat cukup landai, miring ke arah lobang jongkok, mudah dibersihkan dan aman penggunaannya, dilengkapi dengan dinding dan penutup, cukup penerangan dan sirkulasi udara, luas ruangan yang cukup dan tersedia air dan alat pembersih. Tujuan program JAGA (jamban keluarga) yaitu tidak membuang tinja di tempat terbuka melainkan membangun jamban untuk diri sendiri dan keluarga.

Kesehatan lingkungan adalah sangat besar pengaruhnya terhadap kesehatan masyarakat, karena di dalam lingkunan penyebab penyakit dapat dipelihara dan ditularkan. Ruang lingkup kesehatan lingkungan tersebut antara lain mencakup perumahan, pembuangan kotoran manusia 
(tinja), penyediaan air bersih, pembuangan sampah, pembuangan air kotor (air limbah), rumah hewan ternak (kandang) dan sebagainya. Santoso dan Ranti (2004:19) mengemukakan bahwa pemeliharaan kesehatan lingkungan dititikbertakan kepada pengawasan terhadap berbagai faktor lingkungan yang memudahkan timbulnya penyakit atau mempengaruhi derajat kesehatan masyarakat. Hal ini tidak dapat terlepas dari perilaku masyarakat dalam menjaga kebersihan diri dan lingkungannya, termasuk dalam penggunaan jamban keluarga.

Mutmainna (2009:2) menjelaskan bahwa pembuangan tinja perlu mendapat perhatian khusus karena merupakan satu bahan buangan yang banyak mendatangkan masalah dalam bidang kesehatan dan sebagai media bibit penyakit, seperti diare, typhus, muntaber, disentri, cacingan dan gatal-gatal. Selain itu dapat menimbulkan pencemaran lingkungan pada sumber air dan bau busuk serta estetika. Menurut Mutmainna (2009:2) tujuan jamban keluarga yaitu sebagai berikut: "Tidak membuang tinja ditempat terbuka melaingkan membangun jamban untuk diri sendiri dan keluarga. Penggunaan jamban yang baik adalah kotoran yang masuk hendaknya disiram dengan air yang cukup, hal ini selalu dikerjakan sehabis buang tinja sehingga kotoran tidak tampak lagi. Secara periodic Bowl, leher angsa dan lantai jamban digunakan dan dipelihara dengan baik, sedangkan pada jamban cemplung lubang harus selalu ditutup jika jamban tidak digunakan lagi, agar tidak kemasukan bendabenda lain". Dari pendapat tersebut dapat dikatakan bahwa tujuan penggunaan jamban keluarga adalah dilakukan untuk menjaga higienitas lingkungan yang lebih baik, lebih sehat, lingkungan lebih bersih, lebih nyaman dan keselamatan lebih terjaga, serta dapat mencegah timbulnya berbagai penyakit.

Masih ada sebagian masyarakat yang memiliki sikap yang kurang setuju bahkan tidak setuju untuk menggunakan jamban, tidak memiliki jamban, sehingga tidak menutup kemungkinan penularan berbagai macam penyakit akan terjadi. Alasan utama yang selalu diungkapkan masyarakat mengapa sampai saat ini belum memiliki jamban keluarga adalah tidak atau belum mempunyai uang untuk membangun jamban. Namun sebenarnya tidak adanya jamban di setiap rumah tangga bukan semata faktor ekonomi. Tetapi lebih kepada adanya kesadaran masyarakat untuk menerapkan pola hidup sehat (PHBS), jamban pun tidak harus mewah dengan biaya yang mahal. Di samping itu ada faktor lain yang 
menyebabkan masyarakat enggan untuk selanjutnya hinggap di atas makanan sambil membuat atau membangun jamban yaitu membawa kuman penyakit ketergantungan pada bantuan pemerintah Untuk mengubah kebiasaan Perilaku buang dalam hal membangun jamban.

Perilaku buang air besar masih air besar penduduk dibutuhkan waktu yang cukup lama. Suatu kebiasaan baru akan merupakan suatu kebiasaan yang kurang diterima oleh masyarakat apabila kebiasaan menunjang upaya peningkatan kesehatan tersebut dirasakan lebih bermanfaat lingkungan dan kesehatan masyarakat. buang air besar merupakan bagian yang penting dari kesehatan lingkungan. Di hampir sebagian besar negara-negara, pembuangan kotoran manusia yang layak merupakan kebutuhan kesehatan masyarakat yang paling mendesak. Pembuangan yang tidak adekuat dan tidak saniter, berperan dalam pencemaran tanah dan sumber air bersih yang dibutuhkan manusia untuk minum, masak, mandi dan mencuci. Akibat langsung, yaitu meningkatnya insiden penyakit-penyakit tertentu seperti diare, kolera, amuba serta tipus yang ditularkan melalui air yang terkontaminasi.

Selain itu kotoran manusia di permukaan tanah lamakelamaan menjadi kering; setelah kering terbawa tiupan angin bersama-sama debu dan menyebar kemanamana sambil membawa kuman penyakit seperti bakteri, telur cacing, kista amuba dan lain-lain. Di samping itu lalat dan insekta lainnya bisa hingap di atas tinja dan dibandingkan dengan yang lama. Suatu kebiasaan baru untuk dapat diterima masyarakat memerlukan suatu proses yang lama dan panjang, karena menyangkut berbagai faktor antara lain nilai, pensepsi, pengetahuan, sikap dan tradisi.

\section{KESIMPULAN}

Perilaku Hidup Bersih dan Sehat adalah sekumpulan perilaku yang dipraktikkan atas dasar kesadaran sebagai hasil pembelajaran, yang menjadikan seseorang, keluarga, masyarakat mampu menolong dirinya sendiri di bidang kesehatan dan berperan aktif dalam mewujudkan kesehatan masyarakat. Masih ada sebagian masyarakat yang memiliki sikap yang kurang setuju bahkan tidak setuju untuk menggunakan jamban, tidak memiliki jamban. Pembuangan yang tidak adekuat dan tidak saniter, berperan dalam pencemaran tanah dan sumber air bersih yang dibutuhkan manusia untuk minum, masak, mandi dan mencuci. Akibat langsung, yaitu meningkatnya insiden penyakit-penyakit 
tertentu seperti diare, kolera, amuba serta tipus yang ditularkan melalui air yang terkontaminasi.

\section{DAFTAR PUSTAKA}

1. Husni Abdul Gani, dkk. 2015. Perilaku Hidup Bersih dan Sehat (PHBS) Pada Tatanan Rumah Tangga Masyarakat Using (Studi Kualitatif di Desa Kemiren, Kecamatan Glagah, Kabupaten Banyuwangi). dalam jurnal Ikesma: Jurnal Ilmu Kesehatan Masyarakat. Vol 11 No 1

2. Layya, dkk. 2016. Perilaku Hidup Bersih dan Sehat (PHBS) Dalam Tatanan Rumah Tangga Berbasis Kerusakan Akibat Tsunami di Wilayah Kota Banda Aceh. dalam Jurnal Ilmu Kebencanaan (JIKA): Pascasarjana Universitas Syiah Kuala. Volume 3, No. 1

3. Ratna Julianti, dkk. 2018. Pelaksanaan Perilaku Hidup Bersih dan Sehat (PHBS) di Lingkungan Sekolah. dalam Jurnal Ilmiah Potensia: Universitas Bengkulu. Vol 3 No 2

4. Sutarto, dkk. 2019. Pemberdayaan Masyarakat Dalam Meningkatkan Sarana Sanitasi Rumah Tangga (Jambanisasi) Di Desa Binaan Margoagung Kecamatan Jatimulyo Lampung Selatan. dalam LOGISTA: Jurnal Ilmiah Pengabdian kepada Masyarakat. Vol 3 No 2

5. Galih Citrasiwi, dkk. Pembentukan sikap Masyarakat Terhadap Kesehatan Diri Melalui Kampanye 10 Perilaku Hidup Bersih dan Sehat

6. Wiji Oktanasari, dkk. 2017 Faktor Determinan dan Respon Masyarakat Terhadap Pemanfaatan Jamban Dalam Program Katajaga di Kecamatan Gunungpati Semarang. dalam Public Health Perspektive Journal. Vol 2 No 3 Hal 279-286
7. D C M S Putranti dan L Sulistyorini. 2013. Hubungan Antara Kepemilikan Jamban Dengan Kejadian Diare Di Desa Karangagung Kecamatan Palang Kabupaten Tuban. dalam Jurnal Kesehatan Lingkungan Vol. 7, No. 1: 5463

8. Siti Toibah, dkk. 2018. Kinerja Program Pembangunan Jamban Sehat Di Kecamatan Kaliworo. dalam Jurnal Mahasiswa Administrasi Negara (JMAN), Vol. 02 No. 01

9. Otik Widyastutik. 2017. Faktor yang Berhubungan Dengan Kepemilikan Jamban Sehat Di Desa Malikian, Kalimantan Barat. dalam jurnal Ikesma: Jurnal Ilmu Kesehatan Masyarakat. Vol 13 No 1

10. Stephen P. Luby, dkk. xxxx. Broad approaches to cholera control in Asia: Water, sanitation and Handwashing. journal homepage: www.elsevier.com/locate/vaccin.

11. Britta Augsburg, dkk. 2018. Sanitation and child health in India. World Development 107 22-39

12. Herrera, Veronica. (2019). Reconciling global aspirations and local realities: Challenges facing the Sustainable Development Goals forwater and sanitation. World Development 118 106117

13. Valentina Zuin, dkk. 2019. Policy Diffusion in the Rural Sanitation Sector: Lessons from Community-Led Total Sanitation (CLTS). World Development 124 104-643

14. C. Sartori, dkk. 2018. Sanitation of Staphylococcus aureus genotype B- 
positive dairy herds: A field study. Journal of Dairy Science Vol. 101 No. 8

15. Elijah Bisung, Sarah Dickin. (2019). Concept mapping: Engaging stakeholders to identify factors that contribute to empowerment in the water and sanitation sector in West Africa SSM. Population Health 9 100-490

16. Lisa Cameron, dkk. 2019. Scaling up sanitation: Evidence from an RCT in Indonesia. Journal of Development Economics 138. 1-16

17. Shirin Madon, dkk. 2018. The role of community participation for sustainable integrated neglected tropical diseases and water, sanitation and hygiene intervention programs: A pilot project in Tanzania. Social Science \& Medicine 202 (2018) 28-37

18. Lucy Whitley,dkk. 2019. A framework for targeting water, sanitation and hygiene interventions in pastoralist populations in the Afar region of Ethiopia. International Journal of Hygiene and Environmental Health 222 (2019) 1133-1144

19. Sheela S. Sinharoy, dkk. 2019. Review of drivers and barriers of water and sanitation policies for urban informal settlements in low-income and middleincome countries. Utilities Policy 60 (2019) 100957

20. Jo-Anne L. Geere, Paul R. Hunter. 2019. The association of water carriage, water supply and sanitation usage with maternal and child health. A combined analysis of 49 Multiple Indicator Cluster Surveys from 41 countries. International Journal of Hygiene and Environmental Health 223 (2020) 238-247

21. Naci Dilekli, Ignacio Cazcarro. 2019. Testing the SDG targets on water and sanitation using the world trade model with a waste, wastewater, and recycling framework. Ecological Economics 165 (2019) 106376
22. Cairncross, Sandy. xxxx. The public health benefits of urban sanitation in low and middle income Countries. Utilities Policy journal homepage: www.elsevier.com/locate/jup

23. Krishnan, Sneha. 2019. Water, sanitation and hygiene (WASH) and disaster recovery for community resilience: A mixed methods study from Odisha, India. International Journal of Disaster Risk Reduction 35 (2019) 101061

24. Carlos Saiani, Paulo Furquim de Azevedo. 2018. Is privatization of sanitation services good for health?. Utilities Policy 52 (2018) 27-36

25. Godwell Nhamo, dkk. 2019. Is 2030 too soon for Africa to achieve the water and sanitation sustainable development goal? Science of the Total Environment 669 (2019) 129-139 